\section{Consentir incertezas: o consentimento informado e a (des)regulação das tecnologias de reprodução assistida}

\author{
Consenting to uncertainties: informed consent \\ and (de)regulation of assisted reproductive \\ technologies
}

\footnotetext{
${ }^{1}$ Faculdade de Letras, Universidade do Porto, Porto, Portugal.

2 Fundação para a Ciência e a Tecnologia, Lisboa, Portugal.

Correspondência S. M. R. D. Silva Instituto de Sociologia, Faculdade de Letras, Universidade do Porto. Rua Ir. Miss. Espírito Santo, 18, 4o Dto., 4715-340 Braga, Portugal. smrds@sapo.pt
}

\begin{abstract}
This article aims to analyze the characteristics in the creation and utilization of self-knowledge by physicians and "laypersons" involved in assisted reproductive technologies, based on a comparison of their respective discursive practices concerning expectations, uncertainties, and responsibilities associated with these techniques in Portugal. Physicians evaluate the (un)certainties in the application of these techniques based on naturalist and essentialist categories. However, such arguments are then used as an ideological instrument to disguise the lack of a "scientific" explanation for the failures, thereby reproducing the belief in the "miraculous" nature of scientific and technological progress. The lay understanding of the benefits and limitations of these techniques reflects a reverential attitude towards medicine and the rationalist paradigm of the biomedical perspective, although it is possible to glimpse some spaces for autonomy and resistance vis-à-vis the medical proposals. The uncertainties of these techniques are conceptualized as exceptional and intrinsic effects of medical practice, to which one is required to submit individually. Women are particularly identified as the main parties responsible for maximizing the probability of "success" with these techniques.
\end{abstract}

Assisted Reproductive Techniques; Informed Consent; Technological Development
Susana Manuela Ribeiro Dias da Silva 1,2

\section{Introdução}

A exigência de legalização e controle das novas formas de atuação a adotar no âmbito das aplicações das tecnologias de reprodução assistida é potenciada, entre outros aspectos, pela percepção dos respectivos riscos e incertezas, diretos e indiretos, quer para a sociedade, quer para o indivíduo ${ }^{1 .}$.

Em Portugal, a delegação nos profissionais médicos e investigadores e nas comissões de bioética, no Estado e seus agentes e no mercado e na indústria, afiguram-se como a principal resposta às problemáticas colocadas por essas tecnologias. Nesse contexto, torna-se essencial promover a pluralidade dos espaços de debate e de decisão, o que exige o desenvolvimento de um novo paradigma científico e social capaz de sobrepor a emancipação ao conhecimento e à regulação através, por exemplo, da aceitação e revalorização do caos, do controle precário das causas e da falta de controle sobre as conseqüências das ações "científicas" 2.

No fundo, trata-se de compreender os usos sociais e as implicações das tecnologias de reprodução assistida a partir do reconhecimento da existência de um conjunto de processos heterogêneos e contingenciais, cujas interseções, complexidades e (des)regulações originam configurações singulares e incertas, como o aumento da capacidade de ação através de nexos de causalidade cada vez mais complexos e opacos, 
a incapacidade de prever e identificar com precisão as respectivas conseqüências e a transformação dos contornos da informação médica face à emergência de uma medicina probabilística e de gestão das incertezas 3,4 .

De acordo com esse quadro conceitual, todas as formas de produção de conhecimentos são perspectivadas como autoconhecimentos, com caráter local e argumentativo, (re)configurandose o conhecimento criado, usado e distribuído por um conjunto diversificado de atores sociais individuais ou coletivos para dar sentido às respectivas práticas como um novo conhecimento emancipatório e participativo 2,3,5.

Daqui emerge a necessidade de analisar os autoconhecimentos produzidos por médicos e de enfatizar as suas responsabilidades no nível da divulgação da informação e da compreensão da ciência e da tecnologia pelos cidadãos portugueses, de modo a promover um debate público crítico, participativo e plural 6 . Em particular, importa apreender os processos de demarcação entre os diversos sistemas normativos que tentam regular as tecnologias de reprodução assistida no nível da proteção dos direitos dos cidadãos face às práticas científicas e tecnológicas, que será eventualmente garantida pela articulação entre o direito à informação e o direito a consentir ou recusar submeter-se a determinados procedimentos.

Nesse sentido, a lei portuguesa sobre procriação medicamente assistida ${ }^{7}$ proclama como um dos direitos dos beneficiários "ser corretamente informados sobre as implicações médicas, sociais e jurídicas prováveis dos tratamentos propostos" (Art. 12o, al. c.), exigindo que estes sejam "previamente informados, por escrito, de todos os beneficios e riscos conhecidos resultantes da utilização das técnicas de procriação medicamente assistida, bem como das suas implicações éticas, sociais e jurídicas" (Art. 14o, no ${ }^{\circ}$. 2), de forma a poderem prestar um consentimento "livre, esclarecido, de forma expressa e por escrito, perante o médico responsável" (Art. 14o, no. 1). Mais do que um dever deontológico, a obtenção de um consentimento é perspectivada como um direito dos cidadãos, cujo âmago é a prestação de informações "corretas" sobre os respectivos estados clínicos, assim como sobre todos os "benefícios e riscos conhecidos" associados às tecnologias de reprodução assistida e as alternativas existentes $8,9,10$.

De fato, o consentimento informado pode consubstanciar-se como uma estratégia de humanização e democratização das relações entre os atores sociais envolvidos nas tecnologias de reprodução assistida: ao propiciar uma ocasião de comunicação e diálogo entre os médicos e os indivíduos que recorrem a estas técnicas, pode permitir uma maior ponderação das respectivas incertezas e conseqüências, numa atitude de respeito pela autonomia e pelos direitos dos cidadãos. Mas essa prática também pode revelar-se problemática e as suas dificuldades parecem aumentar com a complexidade do aparato biomédico: a assinatura de um documento que deverá conter informações sobre todos os "benefícios e riscos conhecidos” pode criar a imagem de uma prática discursiva meramente contratual que substituirá a oralidade e a interação face a face entre médicos e utilizadores 11,12,13.

Neste artigo procura-se desvendar os contornos das práticas discursivas que dão forma à criação e à utilização dos autoconhecimentos dos médicos envolvidos nestes processos por intermédio de duas estratégias fundamentais: (i) seleção do tipo de informação a transmitir nestes documentos; e (ii) modalidades de gestão e aplicação das noções de incertezas, benefícios e responsabilidades. Importa, em particular, evidenciar a forma como a naturalização das incertezas e a concepção das mesmas como efeitos excepcionais da intervenção médica se articulam, contribuindo quer para a "purificação" dos procedimentos técnicos e dos conhecimentos "científicos", quer para a diluição de responsabilidades.

Ao mesmo tempo, comentam-se as principais modalidades de tradução, reinvenção e atribuição de significado às informações transmitidas nesses formulários nos contextos cotidianos de utilização por meio da análise dos discursos de 14 mulheres e seis homens utilizadores dessas técnicas, obtidos através da realização de entrevistas semi-estruturadas. Essas revelam uma visão predominantemente positiva da ciência e da tecnologia, assim como das capacidades da medicina e da técnica. As representações e as escolhas sociais dos entrevistados surgem dominadas pela semântica das probabilidades, naturalização das incertezas e orientação ativa e individual para as complicações de caráter biológico eventualmente decorrentes desses processos. As mulheres, em particular, identificam-se como as principais responsáveis pela maximização da probabilidade de "sucesso" dessas técnicas.

Interessa, ainda, realçar a emergência de alguns espaços de negociação entre os médicos e as mulheres e os homens envolvidos nessas técnicas, o que poderá configurar novas racionalidades no exercício dos direitos de cidadania no âmbito das tecnologias de reprodução assistida. 


\section{Considerações metodológicas}

Em outubro de 2005, endereçou-se uma carta de apresentação do projeto de investigação que enquadra este texto a todos os responsáveis clínicos dos centros de medicina da reprodução existentes em Portugal, solicitando a concessão de uma entrevista. Foram enviadas 19 cartas e o total das entrevistas realizadas cifrou-se em nove, com amostra em nível nacional, tendo estas decorrido entre novembro de 2005 e fevereiro de 2006. No final da entrevista foi solicitada uma cópia dos formulários de consentimento informado usados em cada um dos centros, tendo a autora reunido, desta forma, 11 formulários utilizados em cinco unidades públicas de medicina da reprodução e em duas clínicas privadas.

Apesar da lei portuguesa prever a criação de um Conselho Nacional de Procriação Medicamente Assistida, que aprovará um documento com as informações que deverão constar do consentimento informado (Art. 30o, no. 2, al. h) 7, este documento ainda não foi aprovado; logo, cada centro é responsável pela elaboração do mesmo, que será assinado pelas mulheres e pelos homens que recorrem aos seus serviços. Estes tendem a ser bastante sucintos (entre uma a três páginas) e apesar da heterogeneidade dos conceitos usados nos títulos, observa-se uma relativa homogeneidade na seleção das problemáticas que contêm, nomeadamente: intervenções técnicas principais no âmbito da inseminação artificial e da fertilização in vitro; criopreservação de embriões; e recepção de esperma de doador.

Neste artigo apenas se analisam as informações relativas às incertezas, benefícios e responsabilidades transmitidas nesses formulários, confrontando-as com as principais modalidades de tradução, reinvenção e atribuição de significado levadas a cabo pelos seus assinantes nos contextos cotidianos de utilização, apreendidas por meio da realização de entrevistas semi-estruturadas.

No caso das mulheres e dos homens com pelo menos uma experiência de técnicas de procriação medicamente assistida, enviou-se uma carta a um conjunto de pessoas conhecidas da autora, solicitando a sua difusão junto a outras pessoas, numa lógica de "bola de neve". A seleção dos entrevistados e a definição do número de entrevistas a realizar efetuaram-se segundo os procedimentos metodológicos da amostragem "teórica", que se caracteriza pelo fato de que se vai adicionando à análise novos dados sempre que tal se revele pertinente do ponto de vista da construção teórica, até se atingir o nível de saturação da informação. Foram realizadas 15 entrevistas, das quais dez foram individuais (nove mulheres e um homem) e cinco foram em casal, com uma duração média de noventa minutos e que decorreram entre os meses de julho de 2005 e fevereiro de 2006. As entrevistas foram integralmente transcritas e analisadas pela autora.

Todos os entrevistados eram casados. Os grupos etários mais representados foram os dos indivíduos dos 35 aos 39 anos de idade $(\mathrm{n}=9)$ e dos 30 aos 34 anos $(n=8)$, sendo o limite inferior das idades correspondente a uma mulher com 30 anos e o limite superior a um casal, onde ambos os cônjuges tinham 43 anos.

No perfil profissional dos entrevistados prevalecem os quadros superiores da administração pública, os dirigentes e os quadros superiores de empresas $(n=7)$, seguidos pelos profissionais de nível intermediário $(n=5)$ e pelo pessoal dos serviços e vendedores $(n=5)$, existindo três homens especialistas das profissões intelectuais e científicas. Os níveis educacionais e de rendimento familiar são relativamente elevados. Onze dos vinte entrevistados detêm um curso superior completo, dois o mestrado e um o doutorado e apenas três entrevistados detêm nove anos de escolaridade. Todos os casais recebem mais de mil Euros por mês, havendo sete agregados familiares com rendimentos entre os 2 e 3 mil Euros por mês e seis com rendimentos mensais superiores a 3 mil Euros.

A análise de conteúdo das estratégias discursivas de médicos e "leigos" e a interpretação dos resultados basearam-se numa abordagem eminentemente qualitativa, tentando associar a análise substantiva à elaboração teórica por meio do levantamento das expressões mais ilustrativas das relações, práticas e representações sociais sobre as expectativas, incertezas e limitações associadas aos usos e aplicações das técnicas de reprodução medicamente assistida 14 .

\section{Estratégias de naturalização das incertezas}

Os textos dos formulários de consentimento informado analisados referem-se, sobretudo, às incertezas dos resultados dos procedimentos associados à execução das tecnologias de reprodução assistida e às probabilidades de ocorrência de um conjunto de situações adstritas a complicações de caráter biológico, muitas vezes classificadas como inerentes às técnicas em causa e/ou ao uso de drogas durante os tratamentos (Tabelas 1 e 2).

A forma como as incertezas são descritas reforça a percepção das mesmas como efeitos excepcionais à prática da medicina e, em particular, intrínsecos à decisão de querer ter um fi- 
Extratos de comunicação de incertezas nos formulários de consentimento informado.

Impossibilidade de garantir o sucesso

Probabilidade de gravidez múltipla

Possibilidade de haver embriões excedentes

Possibilidade de cancelamento do tratamento

Possibilidade de incertezas futuras
"Não há garantia de sucesso"

"Declaram para todos os efeitos que reconhecem ter (...) sido informados sobre os riscos de todas as técnicas praticadas bem como do seu possível insucesso"

"Nenhuma destas técnicas garante que resulte gravidez [a taxa de gravidez por ciclo terapêutico iniciado foi, nesta Unidade, de cerca de $28 \%$ nos últimos 5 anos]"

"Compreendemos e aceitamos que não pode ser dada qualquer garantia quanto ao decurso e desfecho final de uma gravidez obtida por fertilização in vitro ou microinjeção intracitoplasmática"

"Há a possibilidade de gestações múltiplas"

"A transferência de mais do que um embrião condiciona um aumento da possibilidade de gravidez múltipla"

"Existe, portanto, a possibilidade de (...) se obterem mais embriões do que os estritamente necessários para realizar a transferência de embriões (...). Nestas condições, os embriões 'excedentes' podem ser criopreservados [= congelados] e armazenados para utilização posterior. (...) Os potenciais benefícios da congelação são, pois, a possibilidade de realizar transferências sem nova estimulação ovárica, a prevenção de raras situações de gravidade potencial e a redução do risco de obtenção de gravidez múltipla"

"Se tiver havido embriões excedentes adequados, estes poderão ser criopreservados, beneficiando o casal de nova oportunidade de transferência para o útero e gravidez"

"Damos o nosso consentimento para o congelamento de embriões destinados a novas tentativas de gravidez"

"O ciclo de tratamento pode ser cancelado por resposta ovárica inadequada"

"Pode haver necessidade de interromper o ciclo de tratamento (...) por várias razões, a mais freqüente das quais é a resposta deficiente dos ovários à medicação"

"Nós lemos e compreendemos este documento, tal como as informações verbais e escritas adicionalmente fornecidas, e reconhecemos que este texto não pode constituir a expressão completa e exaustiva de todas as situações e intercorrências passíveis de se verificar no futuro"

Fonte: 11 formulários de consentimento informado em contexto de procriação medicamente assistida, cedidos por sete centros portugueses em fevereiro de 2006

lho, o que obriga à procura do equilíbrio entre incertezas e benefícios a partir de uma "gestão racionalizada das probabilidades" por parte dos utilizadores 15. Aliás, a compreensão profana das incertezas eventualmente originadas pelas aplicações dessas técnicas traduz uma dependência do modelo médico-científico dominante ao ser contextualizada num quadro em que predomina a disseminação da semântica das probabilidades e a naturalização das incertezas dos seus resultados, assim como a orientação ativa para as possibilidades de ocorrência de um conjunto de situações adstritas a complicações de caráter biológico (como as conseqüências eventualmente associadas à estimulação hormonal e, embora raramente, as complicações anestésicas e a gravidez ectópica).

Porém, a análise das estratégias de comunicação das incertezas face à impossibilidade de garantir o sucesso, à probabilidade de gravidez múltipla e à possibilidade de haver embriões ex- cedentes e o respectivo confronto com os processos de utilização e reinterpretação patrocinados pelos entrevistados permite evidenciar alguns espaços de demarcação entre esses atores sociais e os médicos, que refletem considerações "científicas" e "não científicas" relacionadas com os discursos e as práticas médicas neste domínio, como se mostrará a seguir.

\section{A impossibilidade de garantir o sucesso}

Nesses formulários é unânime a idéia de que "não há garantia de sucesso", termo aparentemente equiparado a uma gravidez. No entanto, encontram-se divergências na forma de comunicar a possibilidade de não engravidar face à possibilidade de obter uma gravidez - à indicação de taxas de gravidez contrapõem-se expressões vagas e genéricas sem recurso a porcentagens na comunicação da possibilidade de não haver gravidez (como "possível insucesso"). 
Possibilidade de danos físicos para a mulher

Possibilidade de complicações no caso de gravidez

Eventuais riscos da gravidez múltipla

Possíveis impactos nos recémnascidos

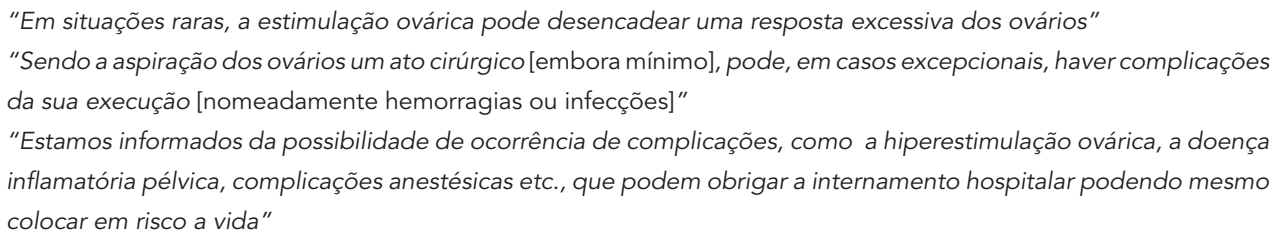

"Em situações raras, a estimulação ovárica pode desencadear uma resposta excessiva dos ovários" "Sendo a aspiração dos ovários um ato cirúrgico [embora mínimo], pode, em casos excepcionais, haver complicações da sua execução [nomeadamente hemorragias ou infecções]"

"Estamos informados da possibilidade de ocorrência de complicações, como a hiperestimulação ovárica, a doença inflamatória pélvica, complicações anestésicas etc., que podem obrigar a internamento hospitalar podendo mesmo colocar em risco a vida"

"Há a possibilidade de (...) abortamento, gravidez ectópica, doenças hereditárias ou malformações congênitas e possibilidade de diagnóstico pré-natal e seus riscos em caso de gravidez"

"Em caso de gravidez, mantém-se o risco de aborto, de gravidez ectópica, ou de malformação fetal, idêntico ao da população em geral"

"Essas gestações poderão conduzir a situações de parto prematuro com conseqüentes riscos para os recémnascidos"

"Embora a maioria dos estudos não tenha detectado aumento da freqüência de malformações nos recém-nascidos resultantes destas técnicas, alguns estudos defendem que essa possibilidade não pode ser completamente excluída"

"A utilização de criopreservação de embriões humanos não revelou até agora um risco superior de anomalias fetais mas é impossivel assegurar a absoluta segurança da técnica"

Fonte: 11 formulários de consentimento informado em contexto de procriação medicamente assistida, cedidos por sete centros portugueses em fevereiro de 2006.

Essas visões refletem-se na forma como os entrevistados tendem a interpretar os “(in)sucessos” das tecnologias de reprodução assistida, uma vez que a obtenção de uma gravidez é perspectivada como dependente de alguns elementos incertos fora do domínio médico e técnico, como "a vontade de Deus" ou da "natureza" (por exemplo, a qualidade dos gametas e dos embriões). Aos médicos é atribuído o papel de mediadores entre esses elementos "naturais" ou "providenciais" e "técnicos", de cuja articulação depende a "fertilidade". Esses profissionais são assim perspectivados como elementos que reproduzem esperanças e encarnam as soluções dos problemas, uma vez que detêm um corpo de conhecimentos técnico-científicos, constituídos em saberes esotéricos, indeterminados e complexos, que informam o seu diferencial de autoridade face aos entrevistados.

\section{A probabilidade de gravidez múltipla}

Os "eventuais riscos" da gravidez múltipla são expressos em termos de morbidade e mortalidade perinatal e infantil e, em menor extensão, materna, como se observa na Tabela 2 .

A possibilidade de vir a ter de fazer uma redução seletiva de fetos e os dilemas da amniocente- se são silenciados nos formulários de consentimento informado, tal como o são outros aspectos considerados não médicos que esta situação pode implicar, nomeadamente o peso financeiro, o desgaste físico e psicológico e a reorganização da vida cotidiana da mãe e/ou do pai. De acordo com o discurso de um dos casais entrevistados, com duas gêmeas de dois anos, esses elementos são descritos por sentimentos como "pânico" e "infelicidade", podendo até provocar a separação do casal, mas não são perspectivados como "riscos", uma vez que escapam à lógica racionalista do paradigma biomédico.

"Começaram a fazer para a ecografia (...) e ele [o médico]: 'São gêmeos'. (...) Eu fiquei em estado de pânico. (...) [Quando nasceram] Primeiro, tive de contratar uma empregada a tempo inteiro, para me ajudar" (Helena, 36 anos, licenciatura, pequena empresária).

"Houve dias em que eu voltava para casa, às vezes, com as meninas pequenas, e lembro-me de estar profundamente infeliz, mas profundamente! (...) Acho que houve uma coisa que pairou toda a gravidez e também o pós-parto, que foi o tal falso positivo" (Mário, 34 anos, mestrado, docente universitário).

"O nascimento delas ia dando cabo da nossa relação. (...) Tivemos quase para nos separar" 
(Helena, 36 anos, licenciatura, pequena empresária).

De fato, a gravidez múltipla só é eventualmente percebida como "algum risco" pelos entrevistados quando esta possibilidade é associada à morbidade e mortalidade perinatal, infantil e materna, à semelhança da tônica dos discursos médicos. Ora, a gravidez múltipla é, em primeiro lugar, uma gravidez, ou seja, algo que os entrevistados procuram quando recorrem às tecnologias de reprodução assistida, o que contribui para a sua aceitação positiva, como nos relata um dos casais entrevistados ao referir-se à gravidez múltipla como uma "alegria dispensável".

"Éalgum [risco], na medida em que, digamos, a Matilde também não tem assim grande arcabouço para ter muitos..." (Henrique, 31 anos, mestrado, docente universitário).

"E até porque nós queremos muito ter um filho, mas não é preciso tanta emoção de uma vez só, não é?" (Matilde, 33 anos, licenciatura, empregada bancária).

"Seria uma alegria dispensável" (Henrique, 31 anos, mestrado, docente universitário).

Em termos gerais, as decisões dos entrevistados quanto à eventual redução da probabilidade de gravidez múltipla tendem a refletir as principais indicações da literatura médica dominante em relação às práticas clínicas neste domínio, nomeadamente o aumento do número de embriões transferidos para o útero à medida que se avança no número de tratamentos realizados, pretensamente com o objetivo de aumentar a probabilidade de "sucesso" e de acordo com a "qualidade" dos mesmos. Ao mesmo tempo, coloca-se a responsabilidade dos eventuais "insucessos" sobretudo na mulher (veja-se o caso da possibilidade de cancelamento do tratamento na Tabela 1) e na "qualidade" do material genético, escamoteando, por exemplo, a insuficiente estandardização dos procedimentos de avaliação, classificação e hierarquização da "qualidade" dos embriões 10,16.

\section{A possibilidade de haver embriões excedentes}

Nos processos de comunicação da possibilidade de haver embriões excedentes não há qualquer discussão sobre a concepção de embrião e sobre o estatuto do mesmo, e omitem-se as referências às possibilidades de investigação ou de doação dos embriões a outro casal e de eventuais manipulações a que estes poderão estar sujeitos, assim como às incertezas associadas ao próprio processo de criopreservação.

Apesar de ser possível limitar a existência de embriões excedentes usando-se, por exemplo, a fertilização apenas do número de ovócitos que possam ser transferidos para o útero da mulher com "segurança" e da criopreservação de ovócitos 8 , a criopreservação de embriões para utilização posterior por parte da mulher que lhes deu origem é apresentada como a solução para a existência "inevitável” de embriões excedentes. Logo, a produção de uma solução para um "problema prático" é reconfigurada numa opção que elimina este mesmo "problema" nos formulários analisados.

Mais, a Sociedade Portuguesa de Medicina da Reprodução 17 entende que a eventual restrição do número máximo de ovócitos a inseminar só poderá ser ajuizada por uma pessoa devidamente qualificada, atendendo às circunstâncias e às especificidades da situação clínica em causa. De fato, o discurso de um dos entrevistados evidencia o reconhecimento da "pressão" exercida por parte da equipe médica para que os "leigos" perspectivem a "normalização" da existência de embriões excedentes como uma conseqüência aparentemente inevitável das aplicações de tecnologias de reprodução assistida, com o objetivo de aumentar a probabilidade de "sucesso" através da seleção dos "melhores" embriões.

"Nós perguntamos e eles [os médicos] disseram: 'Aí nós não podemos implantar mais de três'. (...) E nós dissemos: 'Está bem; então nós não queremos que fecundem mais de três'. Aí houve um bocadinho de pressão para que não fosse assim. (...) E eles depois respeitaram isso, mas houve ali um bocadinho a tentativa de 'Ah, mas já que vai estimular, porque é que não estimula mais, depois tem mais, escolhem-se os melhores e a probabilidade aumenta. (...) Percebemos e a nossa leitura era: Ele quer ter mais sucesso" (Leandro, 36 anos, doutorado, gestor numa empresa de biotecnologia).

Ainda que a maioria dos entrevistados concorde com a criopreservação de embriões, perspectivando-a como uma necessidade inevitável e cujo destino preferencial será a reutilização pela mulher que lhe deu origem, existe um discurso alternativo minoritário, que questiona o desenho da intervenção clínica proposta: tratase de dois homens, um aluno de doutorado em ciências econômicas e um doutorado em gestão (com licenciatura em genética), que procuram uma solução para evitar os embriões excedentes (inseminar o número de ovócitos equivalente ao número de embriões a transferir para o útero, num caso, e propor uma fertilização in vitro em ciclo espontâneo, no outro).

Essas situações são socialmente aceitas como racionais e moralmente corretas, porque permitem reduzir as incertezas por intermédio da ação atenta, responsável e autônoma dos indivíduos, 
o que poderá configurar o emergir de uma nova racionalidade no exercício dos direitos de cidadania no âmbito das tecnologias de reprodução assistida por parte do "leigo perito" 18.

\section{A diluição de responsabilidades}

O processo de naturalização e biologização das incertezas das tecnologias de reprodução assistida encoraja a sua interpretação como riscos, afigurando-se como uma estratégia de racionalização da intervenção técnica e de "purificação" do conhecimento médico neste domínio ao tornar invisíveis as problemáticas sociais, culturais, psicológicas, jurídico-legais e éticas, ao mesmo tempo que reforça a individualização e privatização da responsabilidade pelas incertezas consentidas. As mulheres e os homens que procuram os serviços de medicina da reprodução vêem-se confrontados com a necessidade de decidir correr as incertezas comunicadas; ora, o direito à liberdade de decisão é redirecionado, transformando-se no dever de decidir correr incertezas e consenti-las, assumindo a responsabilidade pelas mesmas (Tabela 3).

A exclusão da responsabilidade médica, em particular, ilustra uma visão contratualista e pragmática da sua atividade, o que tende a reforçar o caráter privatista e crescentemente despersonalizado da mesma. Aliás, são proibidas as cláusulas de exclusão ou limitação da responsabilidade nos formulários de consentimento informado em Portugal, por danos diretos ou indiretos cau- sados à vida, à integridade moral ou física ou à saúde das pessoas 12 .

Os médicos estão diretamente envolvidos nos diversos processos de tomada de decisão e não devem, por isto, ignorar as conseqüências que daí advêm, nomeadamente a assunção de uma atitude não diretiva e co-responsável nas eventuais decisões das mulheres e dos homens com quem lidam. Aliás, a Organização Mundial da Saúde (OMS) sugere que os médicos avaliem a forma como os pacientes compreendem a informação que lhes é facultada, pedindo-lhes, por exemplo, para descrever os objetivos, limitações e benefícios dos procedimentos associados às tecnologias de reprodução assistida nas suas próprias palavras e averiguando os respectivos conhecimentos acerca das alternativas disponíveis, incluindo a alternativa de não se submeter a determinados procedimentos 10 .

As mulheres entrevistadas, em particular, tendem a responsabilizar-se de forma individual e privada pela inexistência de uma gravidez, mesmo quando a causa de infertilidade é "masculina", seja porque não respondem à estimulação hormonal, não "agarram" o embrião, não asseguram os "melhores" estilos de vida após a transferência de embriões, são vulneráveis a determinados mecanismos psicológicos ou pelas dificuldades que a sua idade parece impor. Subjacente a essas representações prevalece a concepção de infalibilidade da medicina e das tecnologias de reprodução assistida, que aparece associada à imagem de "objetividade" e "exatidão", como ilustram os seguintes depoimentos.

Extratos da individualização e privatização das responsabilidades pelas incertezas nos formulários de consentimento informado.

Aceitar os riscos e as limitações das técnicas

Responsabilização pelos embriões excedentes

Aceitar excluir a responsabilidade médica

"Compreendemos e aceitamos as condições, riscos e limitações destas técnicas"

"Temos conhecimento e aceitamos os riscos de hiperestimulação ovárica bem como de gestação gemelar"

"O casal e a [clínica] declaram aceitar a criopreservação de embriões até _ anos, pelo que o casal deverá contatar a [clínica] anualmente"

"Damos o nosso consentimento para o congelamento de embriões destinados a novas tentativas de gravidez. Assumimos a responsabilidade pelos embriões congelados"

"Concordamos em não responsabilizar (...) qualquer dos membros (...) desse hospital por qualquer efeito adverso, embora remoto e imprevisível, resultante do congelamento e conservação dos nossos embriões. Mais, afirmamos o compromisso de não envolver (...) qualquer dos membros (...) desse hospital em qualquer disputa ou litígio respeitante ao destino dos embriões congelados, ou das crianças eventualmente resultantes deste processo"

"Mais, declaram que eximem a [clínica] e qualquer dos elementos da equipe de fertilização in vitro de todas e quaisquer conseqüências que possam resultar do ato médico solicitado"

Fonte: 11 formulários de consentimento informado em contexto de procriação medicamente assistida, cedidos por sete centros portugueses em fevereiro de 2006. 
"Mas se a causa é dele, é ultrapassada pelos tratamentos, certo? (...) Portanto, o mal é meu, que não o consigo agarrar" (Custódia, 35 anos, licenciatura, economista).

“A pós-transferência de embriões até fazer o teste de gravidez são muito complicadas. (...) A sensação que dá é: Qualquer coisa de errado que eu faça nestes 15 dias estou a estragar" (Sandra, 33 anos, licenciatura, gestora).

“Aquilo que é matematicamente certo" (Pedro, 36 anos, 12 anos de escolaridade, empregado comercial).

Aliás, as palavras que encontramos na explicação dos motivos que podem levar ao cancelamento do tratamento (Tabela 1) assentam numa linguagem negativista pelo uso de termos como "resposta deficiente" ou "inadequada" dos ovários, projetando um contexto ideológico que reforça o sentido de inadequação e culpabilização das mulheres.

A "natureza" das mulheres é, dessa forma, reconfigurada como o principal fator de limitação da eficácia da medicina, sendo estas duplamente integradas nas tecnologias de reprodução assistida - por um lado, são eleitas como atores fundamentais no auxílio à produção médica; por outro, são nomeadas como objeto preferencial das práticas médicas. Daí que as mulheres entrevistadas entendam que é seu dever "natural" colaborar nos diversos tipos de intervenção biomédica, reproduzindo o clima de aceitação positiva da dor e da incerteza para fins de maternidade 19 .

As mulheres entrevistadas referem-se freqüentemente ao sofrimento e à dor, quer em termos físicos, quer em termos afetivos e emocionais, e às mudanças na forma e no funcionamento dos seus corpos (e na percepção que deles têm) como características das trajetórias nas tecnologias de reprodução assistida. No entanto, esses processos de dissecação, interferência e transformação dos corpos das mulheres são desvalorizados ao serem perspectivados como uma conseqüência "comum" e "normal" dessas técnicas.

“ $E$ as mulheres não estão preparadas para aquilo que vai acontecer ao corpo delas. Não estão mesmo. (...) Fica-se com um corpo de grávidas sem se estar grávida. (...) [E nunca vos informaram sobre isso?] De todo!" (Pedro, 36 anos, 12 anos de escolaridade, empregado comercial).

“Não! Isso são coisas paralelas, não é? (...) É assim: é comumente. (...) É normal, as pessoas sabem. (...) Eu sabia que ia engordar, não é? Sabia!" (Sandra, 33 anos, licenciatura, gestora).

Mais, os procedimentos experimentais a que as mulheres são sujeitas emergem como uma oportunidade de comprovar, por antecipação, o amor das mesmas pelos potenciais filhos, até porque a "compensação" de ter um filho é racionalizada como um elemento que, a posteriori, irá contribuir para que as mulheres "esqueçam com uma facilidade muito grande" as dores que por ele suportaram.

"É assim, qualquer mulher, se calhar, pensa em ter um segundo filho, porque são daquelas dores que se esquecem com uma facilidade muito grande, porque depois há ali uma compensação. O mesmo acontece quando uma mulher conseguir um filho, vai pensar nisto de outra forma, natural! É evidente que há aqui coisas que não são fáceis, há aqui coisas que doem, claro que doem..." (Matilde, 33 anos, licenciatura, empregada bancária)

\section{Conclusão}

A medicina constrói retoricamente uma imagem de neutralidade e tecnicismo, obscurecendo as ambigüidades e arbitrariedades dos seus processos de criação, interpretação e utilização de determinados produtos científicos. Aliás, muitas das promessas das tecnologias de reprodução assistida dependem da capacidade de mascarar as incertezas, em articulação com a mobilização de um conjunto de expectativas e de direitos em torno do seu impacto futuro 18 .

A linguagem escrita vertida nos formulários de consentimento informado no âmbito da procriação medicamente assistida em Portugal tende a uniformizar e naturalizar a diversidade de discursos existentes, excluindo linguagens alternativas ou exteriores ao sistema biomédico. Mais, as contingências eventualmente ocorridas nessas atividades são deslocadas para fora da esfera das competências e das responsabilidades dos médicos. Os argumentos de caráter naturalista e essencialista são instrumentalizados pelos médicos para eclipsar a ausência de explicação "científica" para os "insucessos" de diversas experiências vividas por mulheres, homens e médicos. Em termos globais, essas estratégias visam a assegurar a imagem de "sucesso" das tecnologias reprodutivas, por um lado, e reforçar a não responsabilidade dos médicos quanto à incerteza dos resultados, por outro.

Essas estratégias têm repercussões nos discursos dos entrevistados, nomeadamente pelo uso de expressões lingüísticas de incerteza, probabilidade e culpabilização, estas últimas presentes sobretudo nas mulheres.

Essas tecnologias são reconfiguradas em diferentes contextos pela multiplicidade de atores sociais por elas mobilizados, como os médicos e os "leigos". De fato, a apreciação da qualidade, eficácia e segurança das tecnologias de reprodu- 
ção assistida resulta de processos contraditórios e complexos, que reclamam uma análise multidimensional, que atenda à heterogeneidade dos conhecimentos e ao dinamismo das expectativas e incertezas por elas potenciadas. Daí a necessidade de desenvolver estratégias flexíveis de avaliação das limitações e implicações futuras dessas técnicas, que representem todos os interesses envolvidos e as necessidades eventualmente em confronto.

Para evitar que a prática do consentimento informado se reduza à formalidade da assinatura de um documento, há que compatibilizar a formulação de padrões que fixem os termos em que se deve prestar a informação com as necessidades, os valores e as expectativas de cada indivíduo concreto, contribuindo para sobrepor a emancipação ao conhecimento e à regulação. Esse é, de fato, um dos maiores desafios que se colocam no âmbito das tecnologias de reprodução assistida.

Desde logo, os diversos intervenientes valorizam informações diferentes, compreendem-nas a partir de quadros de referência individuais e recordam-se delas de forma seletiva, e os "leigos" podem não ter meios que lhes permitam lidar com a quantidade e qualidade da informação eventualmente disponível, pelo que deveria ser prestado um consentimento para cada conjunto de atos médicos. Essas orientações exigem o uso de uma linguagem, oral ou escrita, corrente e perceptível, num processo de comunicação capaz de ultrapassar a ênfase nos critérios meramente técnicos e que atenda aquilo que os cidadãos realmente compreendem a partir das explicações que lhes foram dadas.

Nesse sentido, é essencial analisar as diversas modalidades de reinterpretação das informações prestadas pelos médicos com base na perspectiva dos seus utilizadores. Dessa forma, é possível evitar que os utilizadores dessas técnicas se coloquem numa mera lógica de diagnóstico e tratamento e, ao mesmo tempo, acautelar a criação de sobre-expectativas acerca dos poderes dos médicos, cujas capacidades de atuação prática cotidiana são muitas vezes limitadas e incertas, o que não deixa de contrastar com as necessidades das mulheres e dos homens que recorrem a essas técnicas.

\section{Resumo}

Este artigo visa a analisar os contornos locais de criação e utilização dos autoconhecimentos de médicose "leigos" envolvidos em processos de procriação medicamente assistida a partir do confronto das práticas discursivas destes atores sociais em torno das expectativas, das incertezas e das responsabilidades associadas a estas técnicas em Portugal. Os médicos avaliam as (in)certezas das aplicações dessas técnicas com base em categorias de caráter naturalista e essencialista. Mais, esses critérios são instrumentalizados para eclipsar a ausência de explicação "científica" para os (in)sucessos, reproduzindo a crença no caráter "miraculoso" do progresso científico e tecnológico. A compreensão profana dos benefícios e das limitações dessas técnicas reflete uma atitude reverencial face à medicina e ao paradigma racionalista da perspectiva biomédica, ainda que seja possível vislumbrar alguns espaços de autonomia e resistência face às propostas médicas. As eventuais incertezas dessas técnicas são perspectivadas como efeitos excepcionais e intrínsecos à prática da medicina, aos quais têm de se submeter de forma individual. As mulheres, em particular, identificam-se como as principais responsáveis pela maximização da probabilidade de "sucesso" dessas técnicas.

Técnicas Reprodutivas Assistidas; Consentimento Informado; Desenvolvimento Tecnológico

\section{Agradecimentos}

A autora agradece à Fundação para a Ciência e a Tecnologia o apoio concedido através de uma bolsa de doutorado ainda em curso (SFRH/BD/10396/2002). Agradeço ainda os comentários de Helena Machado e dos dois avaliadores anônimos sobre a primeira versão deste texto. 


\section{Referências}

1. Gonçalves ME. Ciência e direito: de um paradigma a outro. Revista Crítica de Ciências Sociais 1991; 31:89-113.

2. Santos BS. A crítica da razão indolente: contra o desperdício da experiência. Porto: Edições Afrontamento; 2000.

3. Nunes JA. The uncertain and the unruly: complexity and singularity in biomedicine and public health. In: Oficina do CES. Coimbra: Centro de Estudos Sociais; 2003. p. 16.

4. Santos JR. Sobre as fronteiras. In: Santos BS, organizador. Conhecimento prudente para uma vida decente: um discurso sobre as ciências revisitado. Porto: Edições Afrontamento; 2003. p. 511-28.

5. Nunes JA. A pesquisa em saúde nas ciências sociais e humanas: tendências contemporâneas. In: Oficina do CES. Coimbra: Centro de Estudos Sociais; 2003. p. 36.

6. Caraça J. Epicuro proscrito? Ou a ciência, os poderes e a democracia. In: Gonçalves ME, organizador. Ciência e democracia. Venda Nova: Bertrand Editora; 1996. p. 83-90.

7. Portugal. Lei $n^{\circ}$. 32/2006. Regula a utilização de técnicas de procriação medicamente assistida. Diário da República 2006; 26 jul.

8. Andrews LB, Elster N. Regulating reproductive technologies. J Leg Med 2000; 21:35-65.

9. Oliveira G. Temas de direito da medicina. Coimbra: Coimbra Editora; 1999.

10. European Society for Human Reproduction \& Embryology. The interface between medically assisted reproduction and genetics: technical, social, ethical and legal issues. http://www.eshre.com/emc. asp?pageId=632 (acessado em 03/Abr/2007).
11. Menegon VM. Consentindo ambigüidades: uma análise documental dos termos de consentimento informado, utilizados em clínicas de reprodução humana assistida. Cad Saúde Pública 2004; 20:84554 .

12. Oliveira G, Pereira AD. Consentimento informado. Coimbra: Centro de Direito Biomédico; 2006.

13. Rodrigues JV. O consentimento informado para o acto médico no ordenamento jurídico português (elementos para o estudo da manifestação da vontade do paciente). Coimbra: Coimbra Editora; 2001.

14. Anderson P. On doing qualitative research linked to ethical healthcare. London: The Wellcome Trust; 2001.

15. Mendes FR. Risco genético: da ilusão de certeza à disseminação da (ir)racionalidade. In: Carapinheiro G, organizador. Sociologia da saúde: estudos e perspectivas. Coimbra: Pé de Página; 2006. p. 17-45.

16. Land JA, Evers JLH. Risks and complications in assisted reproduction techniques: report of an ESHRE consensus meeting. Hum Reprod 2003; 18:455-7.

17. Sociedade Portuguesa de Medicina da Reprodução. Contributo para a legislação sobre reprodução medicamente assistida. http://www.spmr.pt/ news.htm (acessado em 19/Abr/2006).

18. Webster A. Innovative health technologies and the social: redefining health, medicine and the body. Curr Sociol 2002; 50:443-57.

19. Lupton D. Risk. London: Routledge; 2003.

Recebido em 15/Mai/2007

Versão final reapresentada em 12/Jul/2007 Aprovado em 05/Set/2007 